Original Article

\title{
The effects of the menstrual cycle on the static balance in healthy young women
}

\author{
Byung Joon Lee, PT, MSc ${ }^{1)}$, Ki Hun Cho, PT, PhD²), Wan Hee Lee, PT, PhD³** \\ 1) Department of Physical Therapy, College of Kyungbuk, Republic of Korea \\ 2) Department of Physical Therapy, Uiduk University, Republic of Korea \\ 3) Department of Physical Therapy, Sahmyook University: 26-21 Gongneung 2-dong, Nowon-gu, \\ Seoul 139-742, Republic of Korea
}

\begin{abstract}
Purpose] The purpose of this study was to investigate the effects of the menstrual cycle on the static balance of healthy young women. [Subjects and Methods] Eighteen healthy young subjects (mean age 19.1 years; weight $57.5 \mathrm{~kg}$; height $159.9 \mathrm{~cm}$ ) participated in this study. The Good Balance system was used to measure the postural sway speed and velocity moment of subjects in the static standing posture. Subjects were measured for static balance between 1 and 3 days after menstruation and 13 days after menstruation. [Results] The velocity moment of postural sway was significantly higher at 13 days after menstruation. [Conclusion] Our results indicate that the menstrual cycle affects the static balance of healthy subjects. During the menstrual cycle, intensity for balance exercises in females should be carefully controlled for injury prevention.

Key words: Menstrual cycle, Static balance, Postural sway
\end{abstract}

(This article was submitted Jun. 27, 2017, and was accepted Aug. 13, 2017)

\section{INTRODUCTION}

The percentage of people participating in exercises for the prevention and treatment of various adult diseases is increasing. In Korea, the proportion of persons participating in sports activities more than once a week increased from $45.5 \%$ in 2013 to $59.9 \%$ in 2016 . However, the rate of injury increases as physical activity increases. Sports injuries are more common in women than in men ${ }^{1)}$. Women have more body fat, greater flexibility, wider pelvis, lighter bone, and less muscle strength, and are more prone to the miserable malalignment syndrome than $\mathrm{men}^{2}$. In particular, female athletes are known to be exposed to more sports injury due to insufficient energy utilization, bone loss, and menstrual disturbances ${ }^{3}$.

The menstrual cycle is governed by hormonal changes. Each cycle can be divided into three phases based on events in the ovary (ovarian cycle) or in the uterus (uterine cycle). The ovarian cycle consists of the follicular phase, ovulation, and luteal phase. Estradiol reaches it's lowest in the follicular phase and reaches its peak in the ovulation phase ${ }^{4)}$

Balance ability has been reported to be one of the factors associated with sports injuries ${ }^{5)}$. Balance is affected by various systems such as the sensory, motor, and central nervous systems. Sex hormone receptors are found in bone, skeletal muscle, ligaments, and the nervous system ${ }^{6}$. Relationship between balance ability and hormonal changes in female is important in terms of injury prevention. However, no prior study investigated the relationship up to today. Therefore, this study investigated the effect of the menstrual cycle on the static balance ability of female young adults.

\section{SUBJECTS AND METHODS}

Eighteen healthy women participated in the study. The subjects did not have musculoskeletal or neurological diseases that

*Corresponding author. Wan Hee Lee (E-mail: whlee@syu.ac.kr)

(C2017 The Society of Physical Therapy Science. Published by IPEC Inc.

(c) (1) $($ This is an open-access article distributed under the terms of the Creative Commons Attribution Non-Commercial No Derivatives BY NC ND (by-nc-nd) License. (CC-BY-NC-ND 4.0: https://creativecommons.org/licenses/by-nc-nd/4.0/) 
Table 1. Comparison of the changes between the beginning of the menstruation and ovulation phases $(\mathrm{n}=18)$

\begin{tabular}{lcc}
\hline & Beginning of menstruation & \multicolumn{1}{c}{ Ovulation } \\
\hline Medio-lateral speed $(\mathrm{mm} / \mathrm{s})$ & $3.18 \pm 0.87$ & $4.18 \pm 1.84^{*}$ \\
Anteroposterior speed $(\mathrm{mm} / \mathrm{s})$ & $5.16 \pm 1.00$ & $5.77 \pm 1.50^{*}$ \\
Velocity moment $\left(\mathrm{mm}^{2} / \mathrm{s}\right)$ & $9.89 \pm 6.79$ & $14.01 \pm 10.93^{* *}$ \\
\hline Values are presented as mean \pm standard deviation. & \\
$* \mathrm{p}<0.05, * * \mathrm{p}<0.01$ &
\end{tabular}

could affect balance, and did not take medications that could affect the sex hormones.

The mean age, height, and weight of the subjects were $19.11 \pm 0.9$ years, $159.93 \pm 5.20 \mathrm{~cm}$, and $57.50 \pm 6.62 \mathrm{~kg}$, respectively. Information regarding the study was provided to all of the subjects prior to their participation and written informed consent was obtained. The study was conducted according to the ethical standards of the Declaration of Helsinki.

The Good Balance System (Metitur Ltd., Jyväskylä, Finland) was used for measurement of postural sway in the standing posture. For measurement of postural sway under stable surface conditions, subjects stood on the force plate with their legs spread at shoulder width. The subjects' head movements were minimized by guiding them to gaze at a fixed forward point. The measurement was performed for 30 seconds and analyzed by calculating the average value of three measurements.

Measurements were taken at the time of ovulation (12-13 days after menstruation) and at the beginning of menstruation (1-3 days after menstruation).

The paired t-test was used to analyze static balance ability at the beginning of the menstrual period and ovulation. The significance level was set at 0.05 .

\section{RESULTS}

All subjects completed the experiment. Experimental results showed that there was a significant increase in the postural sway velocity moment and speed at ovulation compared to the beginning of menstruation $(\mathrm{p}<0.05)($ Table 1$)$.

\section{DISCUSSION}

Balance is maintained by the co-action of the sensory (proprioceptive receptor, visual, vestibular organ), nervous (information processing), and motor systems (motion control). Therefore, changes in these systems affect balance.

Estrogen and progesterone receptors are found in bone, skeletal muscle, ligament, and the nervous system, and changes in the sex hormones affect the structure and function of these tissues.

Balance can be divided into static balance and dynamic balancing ability. Postural sway indicate static balance in standing. Postural sway can be expressed as the velocity moment of the center of gravity ${ }^{7}$. The increase of the velocity moment in each direction indicates a lower balance ability ${ }^{8}$.

The results of this study showed that the velocity moment increased significantly when female sex hormone levels were high. This means that higher levels of female sex hormones lead to less balance. Our finding is consistent with the results of previous studies in which there was a significant change in the balance ability and kinesthesia of subjects complaining of premenstrual syndrome according to the menstrual cycle ${ }^{9,10)}$.

However, it reported that the female sex hormones do not affect the anterior cruciate ligament and mechanical properties of the medial gastrocnemius tendon ${ }^{11)}$. In another study, a low level of male sex hormones affected mobility and muscle strength; however, female sex hormones did not ${ }^{12}$. Therefore, female sex hormones do not directly affect the muscles and ligaments regarding the maintenance of balance, but may affect the sensation or nervous systems.

In future studies, it will be necessary to study the effect of the female sex hormones on the sensation and nervous systems. Moreover, when planning exercise programs for women, the menstrual cycle should be considered. During the menstrual cycle with the levels of female hormones being high, a balance training can be a part of exercise programs for females but the intensity should be controlled to reduce risk of injuries.

\section{REFERENCES}

1) Ristolainen L, Heinonen A, Waller B, et al.: Gender differences in sport injury risk and types of injuries: a retrospective twelve-month study on cross-country skiers, swimmers, long-distance runners and soccer players. J Sports Sci Med, 2009, 8: 443-451. [Medline]

2) Casey E, Hameed F, Dhaher YY: The muscle stretch reflex throughout the menstrual cycle. Med Sci Sports Exerc, 2014, 46: 600-609. [Medline] [CrossRef]

3) Barrack MT, Gibbs JC, De Souza MJ, et al.: Higher incidence of bone stress injuries with increasing female athlete triad-related risk factors: a prospective multisite study of exercising girls and women. Am J Sports Med, 2014, 42: 949-958. [Medline] [CrossRef] 
4) Silverthorn DU: Human physiology: an integrated approach, 6th ed. Glenview: Pearson education, 2013, pp 850-890.

5) Nadler SF, Malanga GA, DePrince M, et al.: The relationship between lower extremity injury, low back pain, and hip muscle strength in male and female collegiate athletes. Clin J Sport Med, 2000, 10: 89-97. [Medline] [CrossRef]

6) Griffin LY, Agel J, Albohm MJ, et al.: Noncontact anterior cruciate ligament injuries: risk factors and prevention strategies. J Am Acad Orthop Surg, 2000, 8: 141-150. [Medline] [CrossRef]

7) Cho K, Lee K, Lee B, et al.: Relationship between postural sway and dynamic balance in stroke patients. J Phys Ther Sci, 2014, 26: 1989-1992. [Medline] [CrossRef]

8) Chung J, Kim S, Yang Y: Correlation between accelerometry and clinical balance testing in stroke. J Phys Ther Sci, 2016, 28: 2260-2263. [Medline] [CrossRef]

9) Hammar ML, Lindgren R, Berg GE, et al.: Effects of hormonal replacement therapy on the postural balance among postmenopausal women. Obstet Gynecol, 1996, 88: 955-960. [Medline] [CrossRef]

10) Micussi MT, Freitas RP, Angelo PH, et al.: Is there a difference in the electromyographic activity of the pelvic floor muscles across the phases of the menstrual cycle? J Phys Ther Sci, 2015, 27: 2233-2237. [Medline] [CrossRef]

11) Burgess KE, Pearson SJ, Onambélé GL: Menstrual cycle variations in oestradiol and progesterone have no impact on in vivo medial gastrocnemius tendon mechanical properties. Clin Biomech (Bristol, Avon), 2009, 24: 504-509. [Medline] [CrossRef]

12) Schaap LA, Pluijm SM, Smit JH, et al.: The association of sex hormone levels with poor mobility, low muscle strength and incidence of falls among older men and women. Clin Endocrinol (Oxf), 2005, 63: 152-160. [Medline] [CrossRef] 